\title{
Comparative Assessment of CPET Versus Typical Work-related Activities in Women With and Without Mild COPD*
}

\author{
JOACHIM SCHNEIDER, INES LEE GIESSER, SANDRA LAUX, \\ ULRIKE BRÜCKNER and STEPHANIE SCHNEIDER-LAUTEREN
}

Institute and Outpatient Clinic for Occupational and Social Medicine, University Hospital, Giessen, Germany

\begin{abstract}
Background: Prevalence of chronic obstructive pulmonary disease (COPD) is increasing in Germany. This study examined the work performance of healthy women compared to those with mild COPD. Patients and Methods: Nineteen women suffering from COPD Global Initiative for Chronic Obstructive Lung Diseases stage I and 41 healthy women underwent standardised cardiopulmonary exercise test (CPET) in comparison to 5 typical work-related tasks. Oxygen uptake, carbon dioxide output, ventilation volume, breathing frequency, heart rate and respiratory exchange ratio (RER) were measured. The activities were quantified. Wilcoxon test and ANOVA were calculated using the SPSS software. Results: Patients with COPD had a lower exercise capacity compared to healthy women and also showed lower performance during work-related activities. Patients with $C O P D$ had a lower oxygen uptake $(p<0.001)$, a higher breathing frequency was accompanied by a higher Borg scale. The heart rate and the ventilation volume as a percentage of maximum CPET were significantly higher in patients with COPD. Women suffering from progressive symptoms had lower oxygen uptakes and RER, whilst breathing frequency and Borg scale were elevated. Conclusion: Even at an early stage of the disease, patients with COPD exhibited limitations in work-related tasks.
\end{abstract}

The number of women working has risen steadily in the EU and especially in Germany for the last ten years (1). There

This article is freely accessible online.

*Some of the results are included in the thesis of I. L. Giesser.

Correspondence to: Prof. Dr. med. Joachim Schneider, Institut und Poliklinik für Arbeits- und Sozialmedizin am Universitätsklinikum Gießen, Aulweg 129/III, D-35385 Gießen, Germany. Tel: +49 06419941300, Fax: +49 06419941309, e-mail: Joachim.Schneider@ arbmed.med.uni-giessen.de

Key Words: Women, COPD, work capacity, CPET, work-related tasks. is a particular increase in those aged 60 to 65 years. Around 4 million women currently work in marginal employment. The majority are women over 65 years old, employed in the service sector, retail and gastronomy (2). Over time, it is expected that more and more elderly women will continue to have a working life. Their work performance will be an important issue in the labour market and ought to be evaluated.

Investigations which are tailored to examine typical workplace strain, especially for women, are hard to find. We are not aware of any study that examined the potential work performance of healthy women compared to women with chronic obstructive pulmonary disease (COPD). However, this is a relevant issue, as COPD is one of the leading causes of death worldwide (3).

In Europe, exact data on the prevalence of the disease are not available as there is no registry. According to Blanco et $a l$., the global prevalence of COPD arises to $12.4 \%$. Europe has prevalence rates of $10.8 \%$ in Southern Europe (Spain, Portugal, Italy, Greece, Malta, Cyprus and Turkey) and up to $14.2 \%$ in Western Europe (the Netherlands, Belgium, Luxembourg, France, Ireland and England) (4). In Germany, smoking is one of the main causes of COPD (5). The proportion of the population with COPD over a period of 1 year in Germany is $5.8 \%$ for women, $5.7 \%$ for men, and increases with age (5).

In occupational and social medicine methods, which assess limitations of work, performance plays an important role. Statutory accident insurance assesses individuals for disability pension. Pension insurance assesses the remaining working capability of an individual and is relevant so as to estimate the degree of limitation in work performance. Such limitations usually manifest during physical stress. Exercise intolerance is a typical sign of COPD. Individual physical stress at the workplace is usually not measured. Thus, the determination of work-related limitations should be carried out in specifically designed field tests. These involve sitting, walking, restocking, cleaning the floor, and climbing stairs, thereby carrying weights up to $5 \mathrm{~kg}$. Cardiopulmonary exercise capacity is agedependent. The pensionable age has gradually risen to 67 years 
in Germany. In particular, the chronically ill often cannot work until their pension age. The working capability of healthy, older adults as compared to those who suffer from even mild COPD should be standardised and validated in comparative, workrelated tests, simulating typical job tasks.

Our target was to investigate the remaining work capacity through typical work activities in healthy women over 40 years of age and patients diagnosed with mild COPD. However, the physical strain during every day work activities ought to be examined in detail. An attempt was made to correlate these objective results with the perceived exertion of the Borg scale (6). By comparing typical work activities with the cardiopulmonary exercise test (CPET), we tried to find a reproducible and objective method for estimating the individual residual work capacity. This should allow a better allocation of patients to different referral activities.

\section{Patients and Methods}

Study population. In total, 60 women aged 40 years and older were included: 19 female patients with mild stable COPD (stage I), without exacerbation during the previous 6 weeks, and who had not participated in rehabilitation programs within the previous 6 months. As a control group, 41 normally active and healthy women without diseases which might affect their physical capacity in general were included.

All participants underwent a clinical examination by a physician Competing left-sided heart failure potentially limiting CPET identified by coloured echocardiography including $\mathrm{cw}$ and $\mathrm{pw}$, was an exclusion criterion. Informed consent was obtained from all participants. The study was approved by the Ethics Committee of the Justus-Liebig University in Giessen (Az.: 251/11) with an appendix dated March 5, 2014.

For body composition, the participants were weighed, measured, and their skinfold thickness was evaluated with a caliper in up to seven different regions of the body, using the Jackson/Pollock equations to assess the body density (7). Measurements were conducted by the same researcher to maintain reliability. Fat-free mass (FFM) and fat-free mass index (FFMI) were established using the equations according to Siri (8) and VanItallie et al. (9).

Pulmonary function testing. All pulmonary function tests were performed by trained technicians using a MasterScreen CPX (CareFusion Germany GmbH, Höchberg, Germany) according to the guidelines adjusted for body temperature and pressure-saturated with water vapour. Measurements in which the two best attempts fulfilled the American Thoracic Society (ATS) (10) criteria for reproducibility (an agreement within 5\%) were included in the analysis. The flow volume curve was formed with the envelope method from curves obtained from at least three successive forced expiratory breathing manoeuvres using the standards of the ATS (10). Standard parameters were measured and forced expiratory volume in $1 \mathrm{~s}$ (FEV1) and the forced expiratory volume in $1 \mathrm{~s}$ (FEV1)/forced vital capacity (FVC) ratio (FEV1/FVC) were relevant for this study. Airway resistance $\left(\mathrm{R}_{\mathrm{aw}}\right)$ was measured by body plethysmography (ML/MLpro-Body; CareFusion Germany $\mathrm{GmbH})$. For grading of the pulmonary function, FEV1 was also expressed as a percentage of the predicted value in the reference population as recommended by the guidelines (11). According to the airflow limitations all patients were classified as having mild COPD of Global Initiative for Chronic Obstructive Lung Diseases (GOLD) (12) stage I: FEV1/FVC $\leq 0.7$ and FEV $1 \geq 80 \%$ predicted. Because there is only a weak correlation between FEV1, symptoms and impairment of a patient's health status symptomatic assessment was considered to the refined ABCD combined assessment tool, according to the Global Initiative for Chronic Obstructive Lung Disease (12). Therefore, patients underwent assessment of either dyspnea using the Modified British Medical Research Council (mMRC) Questionnaire or symptoms using measures such as the COPD Assessment Test $\left(\mathrm{CAT}_{\mathrm{TM}}\right)$ including exacerbation history [presented and cited in (12)]. According to these revised GOLD requirements, the patients with COPD were separated into group A with six patients, B with 11 patients, and D with two patients.

CPET. All participants performed an incremental maximal CPET, according to the criteria of the ATS (13). Seated individuals rode an electrically braked cycle ergometer (VIAsprint, type Ergoselect, Ergoline $\mathrm{GmbH}$, Bitz, Germany) at a pedaling rate of 60 rotations per minute, breathing room air. After unloaded pedaling for 3 minutes, the workload was started at $25 \mathrm{~W}$ and increased by $25 \mathrm{~W}$ every 3 minutes. During exercise, ventilation volume $\left(\mathrm{V}^{\prime}{ }_{\mathrm{E}}\right)$, oxygen uptake $\left(\mathrm{V}^{\prime} \mathrm{O}_{2}\right)$ and carbon dioxide output $\left(\mathrm{V}^{\prime} \mathrm{CO}_{2}\right)$ were collected with Oxycon (CareFusion, Höchberg, Germany) measured breath by breath. The breathing frequency $(\mathrm{BF})$, the ventilated volume $\left(\mathrm{V}_{\mathrm{E}}{ }_{\mathrm{E}}\right)$ and the respiratory exchange ratio (RER) were determined. The main objectives were peak performance, maximal oxygen consumption, ventilated volume, breathing frequency and maximum heart rate. Respiratory gas exchanges indices were used for estimating the anaerobic threshold (AT) according to Solberg et al. (14). Twelvelead electrocardiography was conducted and blood pressure was measured at rest, during exercise, and until 5 minutes into the recovery phase. Symptom-limited exercise testing was terminated when the participant reached exhaustion under maximal effort or if defined criteria for stopping according to the ATS were met (13).

Standardised work-related activities. The examinations during taskrelated activities were carried out with the Oxycon mobile (CareFusion Germany GmbH, Höchberg, Germany), a mobile gas exchange measurement system. Each participant carried out five standardised activities at usual speed under supervision, each lasting 6 minutes. Between the activities, the participants were allowed a break. The following work-related activities were performed over 6 minutes as follows:

- Cashier work: Sitting and horizontally moving $2 \times 1 \mathrm{~kg}$ containers on an flat surface; the total distance the weights were horizontally transported was calculated.

-6-Minute Walk: Walking in the corridor on an even floor; the total distance covered was measured.

- Restocking merchandise in shelves: vertical transport by repeatedly lifting a $3.5 \mathrm{~kg}$ container onto a shelf; the frequency of lifting was counted and the total height the weight was lifted was calculated.

- Cleaning the floor: Wiping an even floor with a mop from one end to the other; the frequency of the sweeps and the total length cleaned were recorded.

- Climbing stairs with parcels: Carrying $2 \times 2.5 \mathrm{~kg}$ heavy parcels on both sides, the time taken for the climb and the number of steps taken were recorded, the height of steps was measured and total weight (body weight + weight load) in metres $\times \mathrm{kg} / \mathrm{s}$ was calculated. 
Table I. Anthropometric data and lung function analysis at rest in healthy women and female patients suffering from mild chronic obstructive pulmonary disease (COPD stage I). Mean values and the standard deviation are given. Significant results are printed in bold.

\begin{tabular}{|c|c|c|c|c|c|c|}
\hline \multirow[b]{2}{*}{ Parameter } & \multicolumn{3}{|c|}{ Aged $40-60$ years } & \multicolumn{3}{|c|}{ Aged $>60$ years } \\
\hline & Healthy $(n=29)$ & $\operatorname{COPD}(n=6)$ & $p$-Value & Healthy $(\mathrm{n}=12)$ & $\operatorname{COPD}(n=13)$ & $p$-Value \\
\hline Age (years) & $50.5 \pm 5.5$ & $50 \pm 5.2$ & 0.630 & $69 \pm 7.4$ & $68 \pm 5.4$ & 0.870 \\
\hline Weight (kg) & $69.9 \pm 14.6$ & $80 \pm 17.8$ & 0.136 & $64 \pm 9.8$ & $69 \pm 10.8$ & 0.141 \\
\hline Body mass index $\left(\mathrm{kg} / \mathrm{m}^{2}\right)$ & $24.9 \pm 4.3$ & $27.9 \pm 7.2$ & 0.381 & $23.9 \pm 3.2$ & $26.5 \pm 4.4$ & 0.128 \\
\hline FFM $(\mathrm{kg})$ & $48.6 \pm 6.6$ & $55.7 \pm 7.4$ & 0.040 & $47.1 \pm 4.9$ & $48.2 \pm 4.8$ & 0.479 \\
\hline FFMI $\left(\mathrm{kg} / \mathrm{m}^{2}\right)$ & $14.5 \pm 1.5$ & $16.4 \pm 2.3$ & 0.044 & $14.4 \pm 1.1$ & $14.9 \pm 1.6$ & 0.480 \\
\hline Tobacco consumption, pack-years & $6 \pm 10.1$ & $12.3 \pm 15.9$ & 0.207 & $0.6 \pm 2.0$ & $25.5 \pm 28.7$ & 0.001 \\
\hline FEV1 (1) & $2.9 \pm 0.5$ & $2.2 \pm 0.5$ & 0.024 & $2.4 \pm 0.8$ & $1.8 \pm 0.5$ & 0.026 \\
\hline FEV1/FVC (\%) & $82 \pm 5.6$ & $67 \pm 12$ & 0.001 & $81 \pm 5.5$ & $68 \pm 9$ & 0.001 \\
\hline FEV1 \% predicted & $127 \pm 14.8$ & $91 \pm 26.4$ & $<0.001$ & $141 \pm 14.2$ & $112 \pm 31.6$ & 0.005 \\
\hline $\mathrm{R}_{\mathrm{aw}}(\mathrm{kPa} / \mathrm{l} / \mathrm{s})$ & $0.23 \pm 0.07$ & $0.53 \pm 0.2$ & 0.001 & $0.26 \pm 0.07$ & $0.38 \pm 0.2$ & 0.05 \\
\hline MEF50 (1/s) & $3.4 \pm 0.8$ & $1.8 \pm 1.0$ & 0.001 & $2.7 \pm 1.0$ & $1.3 \pm 0.8$ & 0.002 \\
\hline mMRC dyspnea scale & - & $1 \pm 0.6$ & & - & $2 \pm 0.9$ & \\
\hline $\mathrm{CAT}_{\mathrm{TM}}$ assessment score & - & $11 \pm 7$ & & - & $13 \pm 4.5$ & \\
\hline GOLD group (n) & - & & - & - & & - \\
\hline A & & 2 & & & 4 & \\
\hline $\mathrm{B}$ & & 3 & & & 8 & \\
\hline $\mathrm{D}$ & & 1 & & & 1 & \\
\hline
\end{tabular}

FFM: Fat-free mass, FFMI: fat-free mass index; FEV1: forced expiratory volume in $1 \mathrm{~s} ; \mathrm{R}_{\mathrm{aw}}$ : airways resistance; MEF50: maximal expiratory flow at $50 \%$ of vital flow capacity; mMRC: modified British Medical Research Council questionnaire [presented and cited in (12)]; CAT $\mathrm{TM}_{\mathrm{C}}$ COPD assessment test (presented and cited in 12).

For each task, the perceived exertion was determined with the Borg scale (category scale with ratio properties) with numbers from 0 (no exertion) to 10 (maximal exertion). The scale allows individuals to subjectively rate their level of exertion during exercise (6).

Blood pressure (BP), heart rate (HR), $\mathrm{BF}, \mathrm{V}^{\prime} \mathrm{O}_{2}, \mathrm{~V}^{\prime} \mathrm{CO}_{2}, \mathrm{RER}$, as well as the ventilated volume $\left(\mathrm{V}^{\prime}{ }_{\mathrm{E}}\right)$ were measured. The measurements of the work-related activities were compared to the maximal values recorded during the incremental standard CPET. The field tests and the CPET were never carried out on the same day.

Statistical analysis. Data were analysed using SPSS 20.0 (SPSS Inc, Chicago, IL, USA). The Shapiro-Wilk test was used to analyze the distribution of the lung function parameters. Since a non-normal distribution was found for all groups, the statistical comparisons between the groups were carried out using the non-parametric Wilcoxon test. All $p$-values were obtained using a two-sided test. A comprehensive multifactorial analysis of variance (ANOVA) with repeated measures was calculated. The variables were within-subject factors, and the groups were the between-subject factors. For differences, post-hoc tests were performed with Bonferroni as well as Games-Howell. A p-value of less than 0.05 was considered statistically significant.

\section{Results}

All examined patients suffered from mild COPD, stage I, with a combined COPD assessment predominantly labelled GOLD group A or B. Due to the age-dependency of physical activities, the patients were assigned to groups of 40-60 years or $>60$ years. The anthropometric data are presented in Table I and show mean age of the respective groups did not differ significantly. Younger patients with COPD tended to have a higher body weight, with a significantly higher FFM and FFMI $(p<0.05)$. The group of healthy individuals consisted of more non-smokers than smokers. The mean number of pack years for (ex)-smokers varied widely and was significantly greater in the older group $(p<0.001)$.

In patients with COPD, those aged 40-60 years achieved a maximum power of $104 \mathrm{~W}$, and those $>60$ years $85 \mathrm{~W}$, whereas data for healthy subjects were $129 \mathrm{~W}$ in the younger group and $106 \mathrm{~W}$ in older women (Table II). The younger individuals reached the predicted maximal value by Wasserman et al. (15), women over 60 years of age achieved only $2 / 3$ of the reference values. The computerised determination of the anaerobic threshold was lower in patients suffering from COPD. The difference was significant for the weight-related exercise capacity $(p<0.05)$. In particular, these $>60$ years suffering from COPD had significantly lower physical capacity during the typical work-related activities cashier work (285 m vs. $393 \mathrm{~m})$ and climbing stairs with parcels of $5 \mathrm{~kg}(2,172 \mathrm{~m} \times \mathrm{kg}$ vs. 3,139 $\mathrm{m} \times \mathrm{kg}$ ). The RER did not significantly differ between groups. However, climbing stairs with parcels was perceived as being more exhausting on the Borg scale, especially by the older patients suffering from COPD (8.4 vs. 5.8).

The variables $\mathrm{HR}, \mathrm{BF}, \mathrm{V}^{\prime}{ }_{\mathrm{E}}$, and $\mathrm{V}^{\prime} \mathrm{O}_{2}$ were measured during work-related tasks and compared with the 
in vivo $33: 115-124(2019)$

Table II. Pulmonary function data during cardiopulmonary exercise test (CPET) and work-related tasks in healthy women and female patients suffering from mild chronic obstructive pulmonary disease (COPD). Mean values and the standard deviation are given. Significant results are printed in bold.

\begin{tabular}{|c|c|c|c|c|c|c|}
\hline \multirow[b]{2}{*}{ Parameter } & \multicolumn{3}{|c|}{ Aged $40-60$ years } & \multicolumn{3}{|c|}{ Aged $>60$ years } \\
\hline & Healthy $(n=29)$ & COPD $(n=6)$ & $p$-Value & Healthy $(n=12)$ & COPD $(n=13)$ & $p$-Value \\
\hline Maximal power (W) & $129 \pm 34$ & $104 \pm 19$ & 0.056 & $106 \pm 22$ & $85 \pm 19$ & 0.020 \\
\hline Predicted maximal power $(\%)^{*}$ & $104 \pm 15$ & $114 \pm 20$ & 0.137 & $66 \pm 14$ & $70 \pm 12$ & 0.328 \\
\hline Weight related power, $(\mathrm{W} / \mathrm{kg})$ & $1.89 \pm 0.47$ & $1.37 \pm 0.45$ & 0.040 & $1.70 \pm 0.46$ & $1.24 \pm 0.32$ & 0.019 \\
\hline Power at AT (W) & $102 \pm 30.6$ & $85 \pm 13.7$ & 0.181 & $90 \pm 24.9$ & $73 \pm 23.6$ & 0.096 \\
\hline \multicolumn{7}{|l|}{ Maximal achieved results } \\
\hline Cashier work with $2 \times 1 \mathrm{~kg}(\mathrm{~m})$ & $360 \pm 100$ & $419 \pm 145$ & 0.294 & $393 \pm 106$ & $285 \pm 78$ & 0.007 \\
\hline 6-Minute walk (m) & $610 \pm 76.6$ & $588 \pm 84.9$ & 0.441 & $607 \pm 63.2$ & $549 \pm 65.5$ & 0.055 \\
\hline Restocking with $3.5 \mathrm{~kg}(\mathrm{~m} \times \mathrm{kg})$ & $80 \pm 34.2$ & $61 \pm 14.8$ & 0.175 & $70 \pm 20.6$ & $62 \pm 25.7$ & 0.174 \\
\hline Cleaning $(\mathrm{m})$ & $726 \pm 178.4$ & $727 \pm 165.2$ & 0.759 & $686 \pm 147.3$ & $617 \pm 139.5$ & 0.301 \\
\hline Climbing stairs with $5 \mathrm{~kg}(\mathrm{~m} \times \mathrm{kg})$ & $3460 \pm 956$ & $3007 \pm 660$ & 0.197 & $3139 \pm 868.5$ & $2172 \pm 931$ & 0.019 \\
\hline Climbing stairs with $5 \mathrm{~kg}(\mathrm{~m} \times \mathrm{kg} / \mathrm{s}$ & $16.6 \pm 4.5$ & $15.8 \pm 4.2$ & 0.759 & $14.8 \pm 4.5$ & $11.1 \pm 4.3$ & 0.050 \\
\hline \multicolumn{7}{|l|}{ RER during } \\
\hline CPET at max. & $1.12 \pm 0.06$ & $1.06 \pm 0.89$ & 0.188 & $1.12 \pm 0.52$ & $1.07 \pm 0.61$ & 0.054 \\
\hline Cashier work with $2 \times 1 \mathrm{~kg}$ & $0.89 \pm 0.07$ & $0.84 \pm 0.04$ & 0.880 & $0.89 \pm 0.06$ & $0.88 \pm 0.05$ & 0.568 \\
\hline 6-Minute walk & $0.86 \pm 0.05$ & $0.85 \pm 0.05$ & 0.599 & $0.86 \pm 0.06$ & $0.88 \pm 0.08$ & 0.605 \\
\hline Restocking with $3.5 \mathrm{~kg}$ & $0.89 \pm 0.06$ & $0.86 \pm 0.04$ & 0.246 & $0.89 \pm 0.06$ & $0.88 \pm 0.05$ & 0.430 \\
\hline Cleaning & $0.85 \pm 0.05$ & $0.82 \pm 0.02$ & 0.196 & $0.83 \pm 0.04$ & $0.85 \pm 0.06$ & 0.479 \\
\hline Climbing stairs with $5 \mathrm{~kg}$ & $1.05 \pm 0.08$ & $1.00 \pm 0.10$ & 0.381 & $1.02 \pm 0.11$ & $1.00 \pm 0.10$ & 0.253 \\
\hline \multicolumn{7}{|l|}{ Borg scale (points) during } \\
\hline CPET at max. & $7.2 \pm 1.9$ & $6.2 \pm 1.5$ & 0.169 & $6.4 \pm 2.4$ & $6.5 \pm 1.5$ & 0.912 \\
\hline CPET at AT & $5.1 \pm 2.2$ & $4.2 \pm 1.3$ & 0.301 & $4.4 \pm 2.0$ & $5.1 \pm 2.6$ & 0.418 \\
\hline Cashier work with $2 \times 1 \mathrm{~kg}$ & $1.8 \pm 1.4$ & $0.8 \pm 0.8$ & 0.080 & $1.9 \pm 1.0$ & $1.9 \pm 1.4$ & 0.694 \\
\hline 6-Minute walk & $2.3 \pm 0.8$ & $2.2 \pm 1.0$ & 0.852 & $1.9 \pm 1.3$ & $3.2 \pm 1.9$ & 0.089 \\
\hline Restocking with $3.5 \mathrm{~kg}$ & $4.6 \pm 1.4$ & $3.8 \pm 1.0$ & 0.221 & $4.3 \pm 1.8$ & $5.2 \pm 1.3$ & 0.071 \\
\hline Cleaning & $2.8 \pm 1.5$ & $2.7 \pm 0.8$ & 0.891 & $2.8 \pm 0.9$ & $3.2 \pm 1.3$ & 0.307 \\
\hline Climbing stairs with $5 \mathrm{~kg}$ & $7.1 \pm 1.9$ & $8.2 \pm 1.3$ & 0.183 & $5.8 \pm 1.5$ & $8.4 \pm 1.6$ & 0.001 \\
\hline \multicolumn{7}{|l|}{ Oxygen uptake $(\mathrm{ml} / \mathrm{min})$ during } \\
\hline CPET at max. & $1658 \pm 422$ & $1538 \pm 266$ & 0.237 & $1392 \pm 244$ & $1193 \pm 286$ & 0.073 \\
\hline CPET at AT & $1307 \pm 383$ & $1201 \pm 221$ & 0.576 & $1192 \pm 295$ & $1012 \pm 267$ & 0.074 \\
\hline Cashier work with $2 \times 1 \mathrm{~kg}$ & $486 \pm 127$ & $603 \pm 121$ & 0.255 & $483 \pm 106$ & $463 \pm 87$ & 0.744 \\
\hline 6-Minute walk & $1049 \pm 268$ & $1280 \pm 179$ & 0.137 & $1011 \pm 172$ & $1099 \pm 232$ & 0.870 \\
\hline Restocking with $3.5 \mathrm{~kg}$ & $1067 \pm 293$ & $1233 \pm 264$ & 0.457 & $943 \pm 122$ & $1020 \pm 156$ & 0.301 \\
\hline Cleaning & $885 \pm 327$ & $1024 \pm 250$ & 0.431 & $784 \pm 107$ & $824 \pm 152$ & 0.913 \\
\hline Climbing stairs with $5 \mathrm{~kg}$ & $1726 \pm 386$ & $1703 \pm 325$ & 0.662 & $1537 \pm 239$ & $1376 \pm 343$ & 0.039 \\
\hline \multicolumn{7}{|l|}{ Breathing frequency (/min) during } \\
\hline CPET at max. & $29.8 \pm 6.3$ & $30.2 \pm 2.3$ & 0.809 & $31.1 \pm 6.0$ & $29.1 \pm 6.2$ & 0.549 \\
\hline CPET at AT & $23.8 \pm 4.9$ & $23.3 \pm 4.3$ & 0.942 & $24.3 \pm 3.7$ & $25.3 \pm 6.1$ & 0.926 \\
\hline Cashier work with $2 \times 1 \mathrm{~kg}$ & $22.8 \pm 5.0$ & $23.7 \pm 2.0$ & 0.264 & $22.3 \pm 2.6$ & $22.7 \pm 4.0$ & 0.624 \\
\hline 6-Minute walk & $22.9 \pm 4.5$ & $25.5 \pm 1.7$ & 0.072 & $25.1 \pm 4.1$ & $25.9 \pm 5.3$ & 0.496 \\
\hline Restocking with $3.5 \mathrm{~kg}$ & $27.2 \pm 5.8$ & $27.9 \pm 3.7$ & 0.569 & $26.9 \pm 4.9$ & $27.6 \pm 4.6$ & 0.683 \\
\hline Cleaning & $27.0 \pm 5.1$ & $27.8 \pm 4.3$ & 0.759 & $25.8 \pm 3.6$ & $26.5 \pm 5.5$ & 0.242 \\
\hline Climbing stairs with $5 \mathrm{~kg}$ & $31.1 \pm 5.5$ & $32.7 \pm 2.7$ & 0.743 & $30.3 \pm 4.7$ & $32.4 \pm 4.3$ & 0.301 \\
\hline \multicolumn{7}{|l|}{ Heart rate $(/ \mathrm{min})$ during } \\
\hline CPET at max. & $159.8 \pm 14.2$ & $152.8 \pm 14.3$ & 0.105 & $150.1 \pm 13.2$ & $129.9 \pm 19.8$ & 0.013 \\
\hline $\mathrm{CPET}$ at $\mathrm{AT}$ & $137.5 \pm 19.8$ & $133.0 \pm 7.4$ & 0.368 & $130.3 \pm 16.6$ & $118.6 \pm 23.1$ & 0.218 \\
\hline Cashier work with $2 \times 1 \mathrm{~kg}$ & $94.2 \pm 11.4$ & $94.7 \pm 11.7$ & 0.983 & $89.1 \pm 8.9$ & $83.0 \pm 8.5$ & 0.242 \\
\hline 6-Minute walk & $111.5 \pm 11.4$ & $126.9 \pm 28.4$ & 0.584 & $106.4 \pm 10.6$ & $107.8 \pm 8.2$ & 0.870 \\
\hline Restocking with $3.5 \mathrm{~kg}$ & $121.0 \pm 15.7$ & $135.8 \pm 31.7$ & 0.599 & $111.6 \pm 11.1$ & $110.8 \pm 10.1$ & 0.807 \\
\hline Cleaning & $107.5 \pm 14.4$ & $126.4 \pm 30.1$ & 0.060 & $99.3 \pm 10.6$ & $100.4 \pm 10.3$ & 0.870 \\
\hline Climbing stairs with $5 \mathrm{~kg}$ & $148.8 \pm 14.7$ & $157.36 \pm 22.9$ & 0.896 & $137.73 \pm 9.5$ & $131.0 \pm 13.9$ & 0.050 \\
\hline \multicolumn{7}{|l|}{ Ventilation $(1 / \mathrm{min})$ during } \\
\hline CPET at max. & $57.1 \pm 15.5$ & $53.2 \pm 6.9$ & 0.324 & $50.0 \pm 9.6$ & $47.2 \pm 12.6$ & 0.221 \\
\hline CPET at AT & $39.8 \pm 11.2$ & $37.0 \pm 4.8$ & 0.395 & $37.0 \pm 7.8$ & $36.8 \pm 12.3$ & 0.406 \\
\hline Cashier work with $2 \times 1 \mathrm{~kg}$ & $17.2 \pm 3.9$ & $20.1 \pm 2.9$ & 0.204 & $16.9 \pm 2.6$ & $17.9 \pm 3.4$ & 0.265 \\
\hline 6-Minute walk & $29.1 \pm 7.8$ & $35.7 \pm 4.0$ & 0.073 & $29.2 \pm 7.6$ & $35.4 \pm 6.4$ & 0.057 \\
\hline Restocking with $3.5 \mathrm{~kg}$ & $33.1 \pm 11.2$ & $36.7 \pm 5.5$ & 0.220 & $29.4 \pm 4.6$ & $34.8 \pm 5.2$ & 0.039 \\
\hline Cleaning & $27.8 \pm 10.6$ & $31.1 \pm 5.0$ & 0.381 & $24.5 \pm 4.1$ & $28.7 \pm 4.7$ & 0.050 \\
\hline Climbing stairs with $5 \mathrm{~kg}$ & $54.0 \pm 14.6$ & $55.8 \pm 8.8$ & 0.793 & $47.4 \pm 12.4$ & $50.1 \pm 8.6$ & 0.913 \\
\hline
\end{tabular}

CPET: Cardiopulmonary exercise test; AT: anaerobic threshold; RER: respiratory exchange ratio. *According to Wasserman (15). 
standardised CPET at the anaerobic threshold and at maximum power. Using ANOVA for repeated measurements and post-hoc analysis according to Bonferri as well as Games-Howell, no significant differences were found between the four groups with regard to $\mathrm{V}^{\prime} \mathrm{O}_{2}, \mathrm{BF}$, and $\mathrm{V}_{\mathrm{E}}$. In CPET and climbing stairs, the HR of patients with COPD aged $>60$ years was $130 / \mathrm{min}$ and thus significantly lower $(p=0.013)$ in comparison to healthy individuals of the same age with $153 / \mathrm{min}$. Comparing the four groups over all activities, the HR was significantly lower in those aged over 60 years than in those aged 40 to 60 years $(p<0.01)$, irrespective of being healthy or suffering from mild COPD. On the other hand, women suffering from COPD and over 60 years of age, had a significantly $(p<0.05)$ higher $\mathrm{V}_{\mathrm{E}}$ whilst restocking merchandise in shelves $(35 \mathrm{l} / \mathrm{min} v s$. $29 \mathrm{l} / \mathrm{min}$ ) and cleaning the floor (29 1/min vs. $25 \mathrm{l} / \mathrm{min}$ ).

In comparison to their maximum CPET, patients with COPD often suffered from a higher intensity in work-related tasks than healthy individuals. Patients with mild COPD reached a higher percentage of their achieved maximal value of $\mathrm{V}^{\prime} \mathrm{O}_{2}$ $(p<0.001)$ than healthy women in work-related tasks (Figure $1 \mathrm{~A})$. For the HR, these differences were only found between younger healthy women and women aged $>60$ years suffering from COPD $(p=0.019)$ (Figure 1B). No differences were detected when comparing the $\mathrm{BF}$ (Figure 1C). The $\mathrm{V}_{\mathrm{E}}{ }_{\mathrm{E}}$ in work-related tasks as a percentage of the maximum CPET was significantly higher $(p=0.046)$ for women over 60 years of age in comparison to healthy individuals (Figure 1D). No significant differences were found between groups regarding the Borg scale as a percentage of maximum CPET (Figure 1E).

Regarding the GOLD assessment score (GOLD group A, B, or D), women were not only restricted in maximum V'O2 during CPET, but also during all work-related tasks (Figure $2 \mathrm{~A})$. The same applies for GOLD group D concerning the RER (Figure 2B). The patients of GOLD group D differed significantly $(p<0.05)$ from groups $\mathrm{A}$ and $\mathrm{B}$, both in the maximally achieved RER during CPET and during the 6minute walk, restocking, and cleaning. Contrary to the $\mathrm{V}^{\prime} \mathrm{O}_{2}$ and the RER, the BF was elevated in all but one task (Figure $2 \mathrm{C}$ ). The perceived exertion determined with the Borg scale was also elevated (Figure 2D). Due to the relatively small number of patients and the range of the measured parameters, the differences with respect to GOLD groups were not significant.

\section{Discussion}

Determination of functional impairment in individuals with COPD is necessary before an invalidity pension based on the degree of disability can be rendered. According to the recommendations (16), eligibility for invalidity pension in patients with COPD patients means that moderate or severe physical work is no longer possible. Patients suffering from moderate, severe or very severe COPD according to GOLD classification of airflow limitations stage II, III or IV mostly are retired or unable to work, whilst patients with mild GOLD stage I mainly continue to work. Therefore, our goal was to investigate women with COPD suffering from mild COPD (GOLD stage I).

CPET is used in surveys to determine the remaining working capacity concerning the degree of disability and thus the disability benefit payment after rehabilitation in patients with COPD. The COPD assessment test correlates with health status impairment in COPD (12). The future risk of exacerbation is described by symptoms, exacerbation history and airflow limitations. Because there is only a weak correlation between FEV1, symptoms and impairment of a patient's health status, symptomatic assessment was considered additionally to the refined ABCD assessment tool. In our study, this assessment tool identified mostly COPD of GOLD group A or B.

Exercise intolerance is a typical sign of COPD. The standardised CPET plays an important role in social and occupational medicine, when an impairment of the cardiopulmonary capacity needs to be quantified. The 6-minute walk reflects limitations expected in activities of daily life (ADL) (17). A significant relationship between walking distance and FEV1 and FVC was reported (17). The estimated exercise performance at peak work capacity (18-20) or peak oxygen uptake (21-24) either on a treadmill or cycle ergometer, were shown to be reduced in patients with moderate and severe COPD. In these studies, the predicted FEV1 was reported to be between $37 \%$ (23) and $52 \%$ (18). This was also described for the maximal values of oxygen uptake $(24,25)$, carbon dioxide output (26), oxygen saturation and minute ventilation, as well as for voluntary volume. In our study, we analyzed all relevant parameters in patients with mild COPD stage I (FEV1 predicted $>80 \%$ ) in comparison to healthy persons matching by age. It was our goal to determine these parameters essential for an evaluation not only by a standardised CPET, but also with regard to work-related tasks.

Significant limitations of the (body-weight-related) exercise capacity even in patients with mild COPD in comparison to healthy adults are confirmed in the present study. Investigations concerning limitations in exercise capacities for women suffering from COPD mostly investigated domestic $\operatorname{ADL}(27,28)$. Task-related studies, especially those which estimate the metabolic equivalent (MET), are mostly restricted to male healthy individuals below 60 years of age. Therefore, we also examined women older than 60 years. Herein a wide range of physical activities was analysed, including activities performed whilst sitting and moving weights (cashier work), vertically lifting weights (restocking merchandise in shelves), ascertaining the possible walking distance (6-minute walk), wiping an even floor (cleaning the floor), and climbing stairs with light 

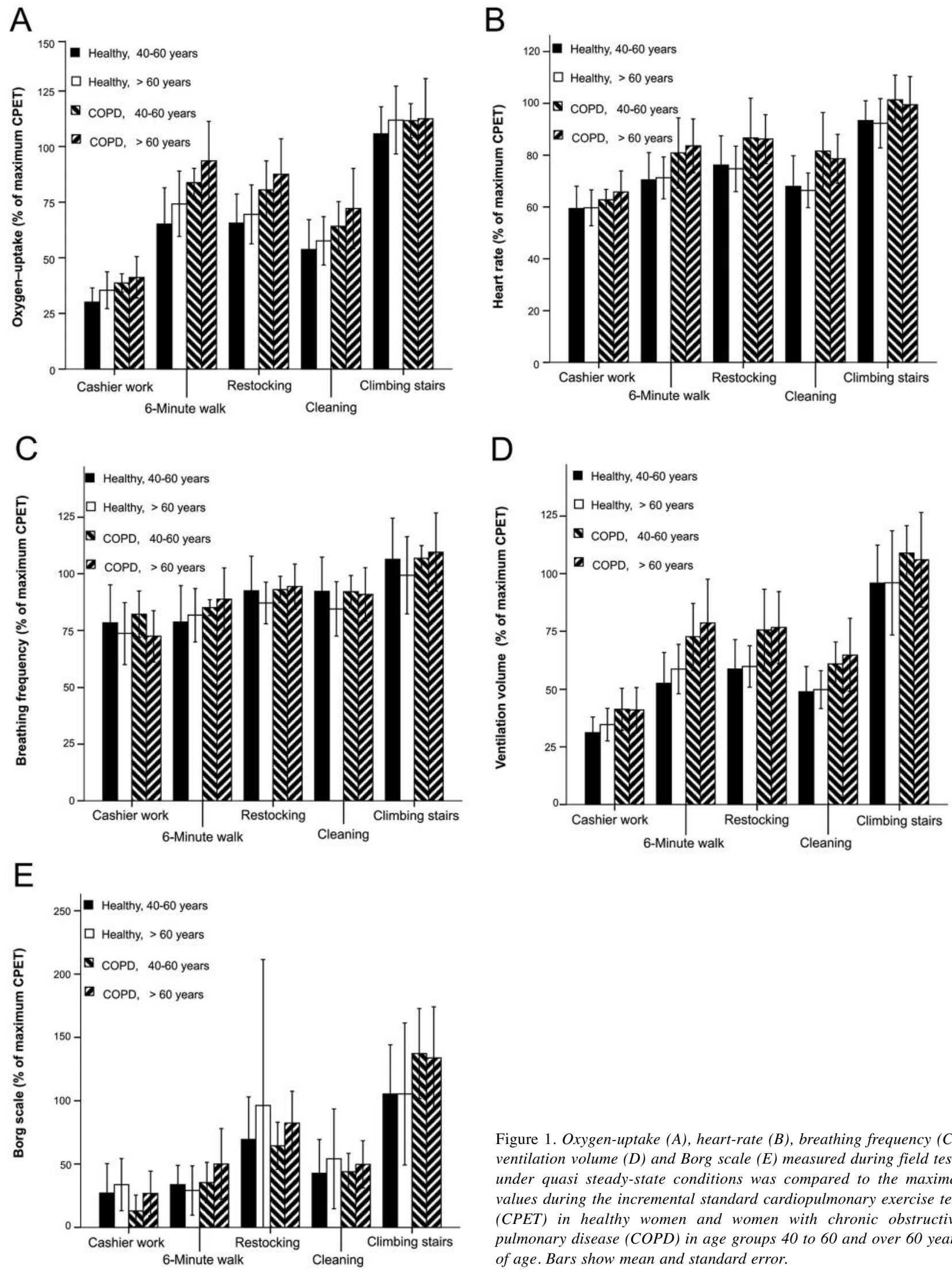

Figure 1. Oxygen-uptake $(A)$, heart-rate $(B)$, breathing frequency $(C)$, ventilation volume $(D)$ and Borg scale $(E)$ measured during field tests under quasi steady-state conditions was compared to the maximal values during the incremental standard cardiopulmonary exercise test (CPET) in healthy women and women with chronic obstructive pulmonary disease (COPD) in age groups 40 to 60 and over 60 years of age. Bars show mean and standard error. 

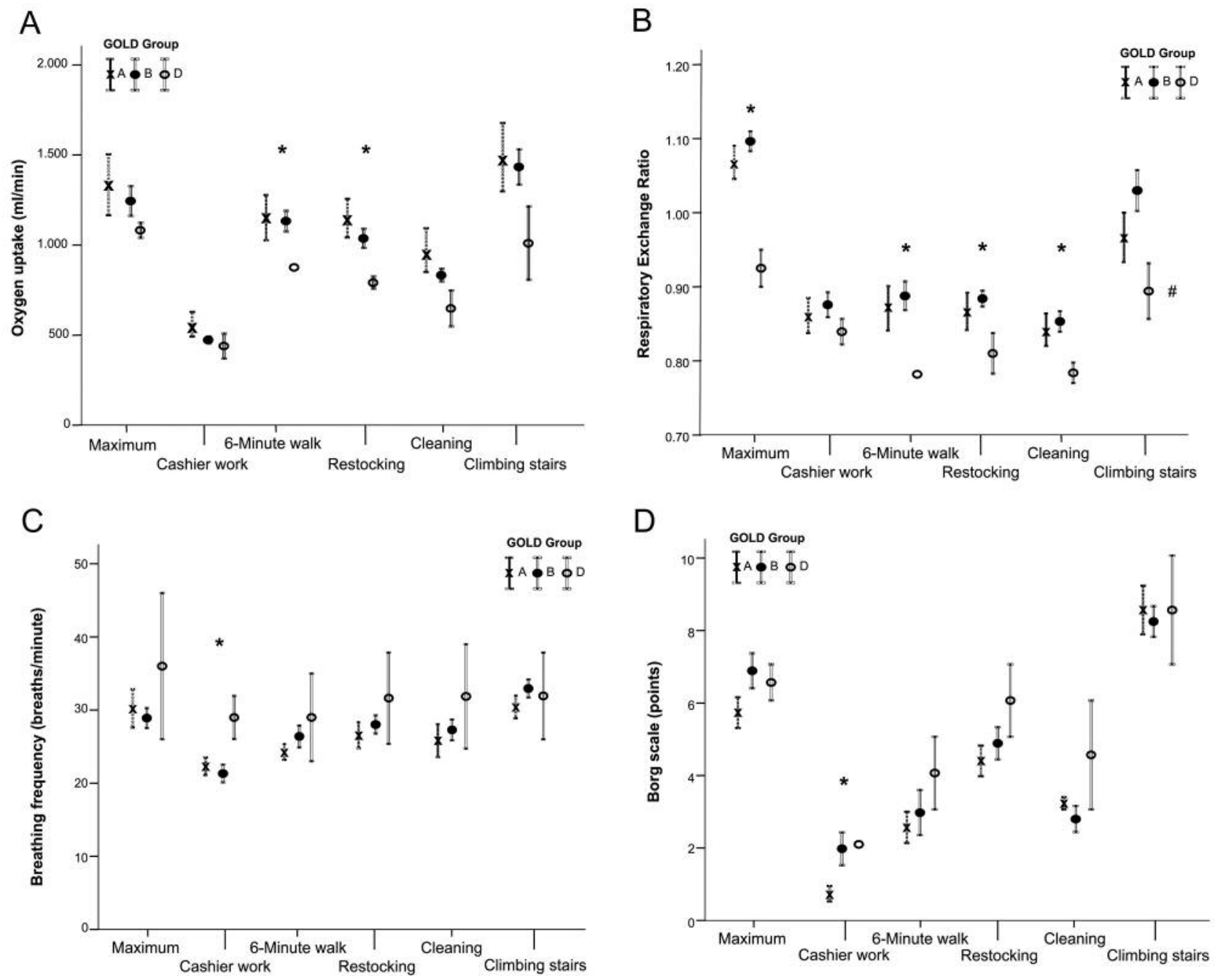

Figure 2. Group dependence of chronic obstructive pulmonary disease (COPD) in women during maximum cardiopulmonary exercise test (CPET) and during work-related tasks. Whiskers show mean \pm standard error for oxygen-uptake (A), respiratory exchange ratio (B), breathing frequency $(C)$, Borg scale $(D)$. Significantly different at $p<0.05$ for *difference between GOLD group A or B and D, and \#difference between all GOLD groups.

weights (climbing stairs with parcels). Merely Kozey et al. examined general physical activities such as climbing stairs, walking, and transporting a box of $6 \mathrm{~kg}$ weight. In this regard, hardly any studies are found for women at all (29). Accordingly, our study explores these issues. With respect to the influence of age dependence of nearly all physical activities, we examined 40- to 60-year-old women and over 60 -year-old subjects with and without COPD. Subsequently they carried out the five above mentioned field tests and quasi steady condition.

The collective showed that those aged 40-60 years with COPD had a higher body weight, increased FFM and FFMI. Even mild COPD results in significant impairment in daily activities $(17,30)$. In our study patients with mild COPD, even in GOLD group A or B, achieved lower physical results in the 6-minute walk, restocking and climbing stairs. According to van Helvoort et al. (31), and Schneider and Funk (32) however, patients with COPD had a lower power during CPET. Patients with COPD stage II and higher were reported to be usually less physically active than healthy subjects of the same age group (17). The older patients with COPD also showed significantly lower exercise capacity compared to healthy people of the same age ( $>60$ years) when climbing stairs with weights and in the cashier task (Table II).

With age, HR at rest and under maximum load decreases (33). In our study, the HR was lower among the older participants than the younger ones. Significant differences 
between the patients and the age-matched control groups were found for maximal CPET and climbing stairs with weights (Table II). Resting BF increases significantly with the severity of COPD (33). We were also able to confirm this observation with work-related activities for women suffering from mild COPD GOLD group A and B.

Oxygen consumption is not only dependent on the basal metabolic rate, but in particular on the work performed and on age (34). The $\mathrm{V}^{\prime} \mathrm{O}_{2}$ peak correlates significantly with the physical performance, quality of living, and everyday life (35).

According to van Helvoort et al. (31), as well as Schneider et al. (32), oxygen uptake at the same work load is comparable in healthy and ill patients. Whilst performing identical work rates at CPET, discrimination between patients with different GOLD stages and healthy individuals was not possible (32). In the present study, it is notable that the oxygen uptake during the task-related activities in patients with COPD was lower in a group-dependent manner confirming the patient-reported outcome in the revised COPD assessment tool (Figure 2A). Mild COPD resulted in significant impairment of oxygen uptake in daily activities (17, 30). According to Vaes et al. (27) patients with progressive GOLD classification had the lowest task-related oxygen uptake accompanied by higher perceived exertion during domestic ADL. This is consistent with other studies, in which patients with even mild COPD had decreased oxygen uptake in the CPET $(36,37)$ and in ADL (stair climbing, warehousing, vacuuming) (30).

We additionally analysed the oxygen uptake as a percentage of the maximum CPET. Patients suffering from mild COPD used a significantly higher proportion of the peak $\mathrm{O} 2$ uptake during CPET in cashier work, restocking, the 6-minute walk and cleaning than the healthy women (Figure 1A), moreover the activities were accomplished at a lower intensity.

In regard to the ADL, Vaes et al. (28) and van Helvoort et al. (31) came to the same conclusion. Van Helvoort et al. described how in patients suffering from early-stage COPD, the relative oxygen consumption as a percentage of the peak was increased compared to healthy individuals in various ADL (climbing stairs $71 \%$ vs. $67 \%$, vacuum cleaning $47 \%$ vs. $40 \%$, restocking cupboard $69 \%$ vs. 62\%) (31). This was accompanied by higher task-related Borg dyspnoea scale in the range of 3 to 6 (28).

Consistent with previously reported results, the maximum ventilated volume of patients with COPD was lower than that of healthy individuals, depending on the stage of the disease (32). At the same work rate, there were no significant differences between diseased and healthy women (32). For men, however, Schneider-Lauteren et al. demonstrated that climbing stairs significantly increased ventilation (38). When climbing stairs with weights, the ventilation was also increased, however, not significantly. During restocking, cashier work, cleaning, and the 6-minute walk, the ventilation volume as a percentage of peak ventilation during CPET in patients with COPD was higher than those in healthy women (Table II).

During physical activities such as climbing stairs, vacuum cleaning and placing groceries into a cupboard, van Helvoort et al. confirmed a higher ventilation in patients with COPD in comparison to the healthy control group. A pathological deadspace ventilation proven under physical exercise is compensated by an increased ventilation (31). The increased (relative) ventilation leads to dyspnea. In dependence of the ADL, peak ventilation was reported to be between $40 \%$ and $80 \%$ (28). Results showed no sex-related differences. Correspondingly, our study also showed a significantly higher ventilated volume as a percentage of the peak ventilated volume during work-related activities in all patients with COPD when compared to healthy women (Figure 1D).

In patients with COPD, ventilatory capacity is limited. In the present study it is notable that the breathing frequency increased over all activities (Figure 2C) in a GOLD groupdependent manner. Ofir et al. also showed an increase in the breathing frequency of sick patients, thus requiring higher ventilation (36).

Regarding the RER, in all groups no significant differences were detected during work-related activities (Table II). In our study, the Borg scale was used to indicate perceived exertion. In patients with COPD, the severity of dyspnea plays a role in the quantification of fatigue.

Patients with COPD had task-related Borg dyspnea scores in the range of 3 to 6 and used up to $100 \%$ of their peak in CPET for different ADLs (28). In our study, climbing stairs was indicated by all participants as having the highest Borg scale (Figure 1E; Table II). Particularly static activities, such as lifting, cleaning, cash work, and restocking, were accompanied by higher Borg scales relatively to the peak CPET. Again, a group-dependence was found (Figure 2D). With increasing physical stress, Mador et al. showed that the Borg scale in patients suffering from COPD does not necessarily correlate with the physiological parameters of the strain, so that its value is limited (39). Even in studies performed on healthy volunteers, the correlation between objective intensity of exercise and subjective fatigue was low (40).

In conclusion, women with mild COPD had a lower performance in all physical tasks than women without COPD. In our study, we reproduced several typical work-related activities and demonstrated that limitations were not only detectable in CPET, but also in tasks at the workplace which are considered as light physical activities. Besides the classification of severity of airway obstruction (FEV1 in \% predicted) patients health status and the risk of future events classified with GOLD group ABCD are also associated with functional disorders in a group-dependent manner. Particularly 
static activities were associated with greater subjective exhaustion. Our results provide additional information for the patient's workplace, which has not been mapped with ADL. The activities represent a wide range of tasks. This will allow a more comprehensive assessment of possible work performance enabling a more suitable recommendation for referral professions in patients suffering from COPD.

\section{Conflicts of Interest}

All Authors declare no financial conflicts. There was no commercial funder. All Authors are employees of the Federal University in Gießen.

\section{Acknowledgements}

All Authors hereby thank all our study participants, without whom our research work would not have been possible.

\section{References}

1 Statistisches Bundesamt: (Internet): Arbeitsmarkt auf einen Blick - Deutschland und Europa. Wiesbaden 2016. Available from: https://www.destatis.de/DE/Publikationen/Thematisch/Arbeitsma rkt/Erwerbstaetige/BroeschuereArbeitsmarktBlick001002216900 4.pdf?_blob=publicationFile (cited 2018 April 16).

2 Deutsche Rentenversicherung Knappschaft-Bahn-See/MinijobZentrale (Internet). 1. Quartalsbericht 2017 - Diagramme und Tabellen. Available from: https://www.minijob-zentrale.de/DE/ 02_fuer_journalisten/02_berichte_trendreporte/quartalsberichte/1_2 017_2.pdf?_blob=publicationFile\&v=6 (cited 2018 April 16).

3 WHO Chronic obstructive pulmonary disease (COPD): Fact sheet November 2017. Available from: http://www.who.int/ mediacentre/factsheets/fs315/en/ (cited 2018 April 15).

4 Blanco I, Diego I, Bueno P, Fernández E, Casas-Maldonado F, Esquinas C, Soriano JB and Miratvitlles M: Geographical distribution of COPD prevalence in Europe, estimated by an inverse distance weighting interpolation technique. Int J Chron Obstruct Pulmon Dis 13: 57-67, 2017.

5 Steppuhn H, Kuhnert R and Scheidt-Nave Ch: 12-month prevalence of known chronic obstructive pulmonary disease (COPD) in Germany. Robert-Koch-Institut, Berlin. J Health Monit 2(3): 43-50, 2017.

6 Borg G: Perceived exertion as an indicator of somatic stress. Scand J Rehabilitation Med 2: 92-98,1970.

7 Jackson AS, Pollock ML and Ward A: Generalised equations for predicting body density of woman. Med Sci Sports Exerc 12: 175-182, 1980.

8 Siri WE: Body composition from fluid spaces and density. In Techniques for Measuring Body Composition. Ed. By J. Brozek and A. Henschel. Washington D.C. Natl Acad Sci: 223-224, 1961.

9 VanItallie TB, Yang MU, Heymsfield SB, Funk RC and Boileau RA: Height-normalized indices of the body's fat-free mass and fat mass: potentially useful indicators of nutritional status. Am J Clin Nutr 52: 953-959, 1990.

10 American Thoracic Society/American College of Chest Physicians: ATS/ACCP Statement on cardiopulmonary exercise testing. Am J Respir Crit Care Med 167: 211-277, 2003.
11 Quanjer PH, Stanojevic S, Cole TJ, Baur X, Hall GL, Culver BH, Enright PL, Hankinson JL, Ip MS, Zheng J, Stocks J and ERS Global Lung Function Initiative: Multi-ethnic reference values for spirometry for the 3-95-yr age range: the global lung function 2012 equations. Eur Respir J 40: 1324-1343, 2012.

12 Global initiative for chronic obstructive lung diseases: Global strategy for the diagnosis, management and prevention of chronic obstructive pulmonary diseases. 2017 Edition. Available from: http://goldcopd.org/wp-content/uploads/2017/11/GOLD2018-v6.0-FINAL-revised-20-Nov_WMS.pdf (cited 2018 April $11)$.

13 American Thoracic Society: Standardization of spirometry 1994 update. Am J Respir Crit Care Med 152: 1107-1136, 1995.

14 Solberg G, Robstad B, Skjønsberg $\mathrm{OH}$ and Borchsenius F: Respiratory gas exchange indices for estimating the anaerobic threshold. J Sports Sci Med 4: 29-36, 2005.

15 Wasserman K, Hansen JE, Sue DY, Stringer WW and Whipp BJ: Principles of exercise testing and interpretation: including pathophysiology and clinical applications, 4th edition Philadelphia. Lippincott and Williams and Wilkens, 2005.

16 Deutsche Rentenversicherung. Leitlinie für die sozialmedizinische Begutachtung- Leistungsfähigkeit bei chronisch obstruktiver Lungenerkrankung (COPD) und Asthma bronchiale. January 2010. Available from: https://www.deutsche-rentenversicherung.de/ Allgemein/de/Inhalt/3_Infos_fuer_Experten/01_sozialmedizin_fors chung/downloads/sozmed/begutachtung/leitlinie_leistungsfaehigkei t_lunge_langfassung_pdf.pdf?__blob=publicationFile \& $v=6$ (Accessed: 18.10.2018).

17 Amorim PB, Stelmach R, de Carvalho CRF, Fernandes FLA, de Carvalho-Pinto RM and Cukier A: Barriers associated with reduced physical activity in COPD patients. J Bras Pneumol 40: 504-512, 2014.

18 Luxton N, Alison JA, Wu J and Mackey G: Relationship between field walking tests and incremental cycle ergometry in COPD. Respirology 13: 856-862, 2008.

19 Cavalheri V, Hernandes NA, Camillo CA, Probst VS, Ramos D and Pitta F: Estimation of maximal work rate based on the 6minute walk test and fat-free mass in chronic obstructive pulmonary disease. Arch Phys Med Rehabil 91: 1626-1628, 2010.

20 Kozu R, Jenkins S, Senjyu H, Mukae H, Sakamoto N and Kohno S: Peak power estimate from 6-minute walk distance in Asian patients with idiopathic pulmonary fibrosis and chronic obstructive pulmonary disease. Respirology 15: 706-713, 2010.

21 Chuang ML, Lin IF and Wasserman K: The body weightwalking distance product as related to lung function, anaerobic threshold and peak VO2 in COPD patients. Resp Med 95: 618626, 2001.

22 Carter R, Holiday DB, Nwasuruba C, Stocks J, Grothues C and Tiep B: 6-Minute walk work for assessment of functional capacity in patients with COPD. Chest 123: 1408-1415, 2003.

23 Hill K, Jenkins SC, Cecins N, Philippe DL, Hillmann DR and Eastwood PR: Estimating maximal work rate during incremental cycle ergometry testing from six-minute walk distance in patients with chronic obstructive pulmonary disease. Arch Phys Rehabil 89: 1782-1787, 2008.

24 Poersch K, Berton DC, Canterle DB, Castilho J, Lopes AL, Martins J, Oliveira AR and Teixeira PJ: Six-minute walk distance and work relationship with incremental treadmill cardiopulmonary exercise test in COPD. Clin Resp J 10: 1752$1769,2012$. 
25 Christensen CC, Ryg M, Edvardsen A, Skumlien S and Hallén $\mathrm{J}$ : Higher metabolic reserve capacity in COPD patients than healthy subjects. Scand J Med Sci Sports 6: 857-864, 2009.

26 Wang H, Xu Q, Ding H, Xiao Y, Liu XX, Fan J and Zhang L: Measurement of alveolar arterial partial pressure of oxygen difference in patients with chronic obstructive pulmonary disease both at rest and during maximal exercise. Chin Med J 87: 31923195, 2007.

27 Vaes AW, Wouters EFM, Franssen FME, Uszko-Lencer NHMK, Stakenborg KHP, Westra M, Meijer K, Schols AMWJ, Janssen PP and Spruit MA: Task-related oxygen uptake during domestic activities of daily life in patients with COPD and healthy elderly subjects. Chest 140: 970-979, 2011.

28 Vaes AW, Franssen FME, Meijer K, Cuijpers MWJ, Wouters EFM, Rutten EPA and Spruit MA: Effects of body mass index on task-related oxygen uptake and dyspnoe during activities of daily life in COPD. plos one. 7(7): e41078, 2012.

29 Kozey SL, Lyden K, Howe CA, Staudenmayer JW and Freedson PS: Accelerometer output and MET values of common physical activities. Med. Sci Sports Exerc 42: 1776-1784, 2010.

30 Gonzalez-Moro RJM, de Lucas RP, Izquierdo AJL, López-Muñiz BB, Díaz AE, Ribera X and Martín A: Impact of COPD severity on physical disability and daily living activities: EDIP-EPOC I and EDIP-EPOC II studies. Int J Clin Pract 63: 742-750, 2009.

31 van Helvoort HAC, Willems LM, Dekhuijzen PNR, van Hees HWH and Heijdra YF: Respiratory constraints during activities in daily life and the impact on health status in patients with early-stage COPD: a cross-sectional study. NPJ Prim Care Respir Med 26: 16054, 2016.

32 Schneider J and Funk M: Submaximal spiroergometric parameters are uneffected by severity of chronic obstructive pulmonary diseases. In Vivo 27: 835-842, 2013.

33 Kostis JB, Moreya AE, Amendo MT, Di Pietro J, Cosgrove N and Kuo PT: The effect of age on heart disease. Studies by ambulatory electrocardiography and maximal exercise stress test. Circulation 65: 141-145, 1982.
34 Schneider J: Age dependency of oxygen uptake and related parameters in exercise testing: an expert opinion on reference values suitable for adults. Lung 191: 449-458, 2013.

35 Berry MJ, Adair NE and Rejeski WJ: Use of peak oxygen consumption in predicting physical function and quality of life in COPD patients. Chest 129: 1516-1522, 2006.

36 Ofir D, Laveneziana P, Webb KA, Lam YM and O'Donnell DE: Mechanisms of dyspnea during cycle exercise in symptomatic patients with GOLD stage I chronic obstructive pulmonary disease. J Respir Crit Care Med 177: 622-629, 2008.

37 Chin RC, Guenette JA, Cheng S, Raghavan N, Amornputtisathaporn N, Cortés-Télles A, Webb KA and O'Donnell DE: Does the respiratory system limit exercise in mild chronic obstructive pulmonary disease? Am J Respir Crit Care Med 187: 1315-1323, 2013.

38 Schneider-Lauteren S, Gehrke D, Armbruster U, Blanarsch D and Schneider J: Leistungsfähigkeit von älteren Erwachsenen mit und ohne chronisch-obstruktiven Atemwegserkrankungen. Zbl Arbeitsmed 65: 315-322, 2015.

39 Mador MJ, Rodis A and Magalang UJ: Reproducibility of Borg scale measurements of dyspnea during exercise in patients with COPD. Chest 107: 1590-1597, 1995.

40 Muyor JM: Exercise intensity and validity of the ratings of perceived exertion (Borg and OMNI Scales) in an indoor cycling session. J Hum Kinet 31: 93-101, 2013.
Received September 28, 2018

Revised October 23, 2018

Accepted October 26, 2018 